\title{
Study of Adolescent Stress In Relation To Grade, Gender and Perceived School and Home Environments
}

\author{
Dr Monika M. Dass ${ }^{1} *$
}

Keywords: Adolescent, Stress, Grade, Gender, Perceived School, Home Environments.

\section{BRIEF REVIEW OF LITERATURE}

Adolescence is a developmental transition between childhood and adulthood. Typically, we view adolescence beginning at puberty and ending at 18 or 21 years. There are several theories of adolescence; some of them are: Hall (1916) - period of storm and stress; Freud (1948) psychosexual development; Bandura (1964) - human development is a continuous process not divided into stages; and, Kohlberg (1963) - cognitive development precedes moral development.

\section{Adolescence and Stress}

Parfenoff and Jose (1989) - results indicated that daily stressors or hassles were a better predictor of children's self-rated anxiety than life events; results also indicated that as the child experienced a life event, daily stressors or hassles increased. Bouma (2010) - discovered that girls react differently to stress than boys; there was no difference in the amount of stress the teenagers themselves said they experienced. Ying et al., (2010) - state that boys experienced high levels of stress from school, family, health, and romantic domains, while girls suffered a higher level of peer stress.

\section{School Environment}

Liang and Spencer's (2011) - study indicates that higher levels of school stress are significantly related to higher levels of emotional problems and other problems. Manoharan and Sundaram (2003); Mohanty and Pani’s (1979) - significant and moderate relationship between classroom climate and teachers teaching effectiveness, as perceived by students was found. Dinesh and Kumari (2010) - level of stress in children has significant relationship with their academic competence irrespective of their gender difference. Lele and Sachdev (2001) - academic performance and perception of academic climate were found to be negative and highly significant among the secondary school students. Verma et al., (2002) - schoolwork generates negative emotions in adolescents as reflected in their low affect state, low activation level, low experience of choice, and high experience of social anxiety. Mishra (2002) - boys and girls differed significantly in their perception of classroom environment on two dimensions i.e.,

\footnotetext{
${ }^{1}$ Psychological Author

*Responding Author

(c) 2016 I M Dass; licensee IJIP. This is an Open Access Research distributed under the terms of the Creative Commons Attribution License (http://creativecommons.org/licenses/by/2.0), which permits unrestricted use, distribution, and reproduction in any Medium, provided the original work is properly cited.
} 


\section{Study of Adolescent Stress In Relation To Grade, Gender and Perceived School and Home Environments}

interpersonal relationship, goal orientation and on total perception. Boys perceived classroom environment to be better than girls in all the dimensions. Waxman and Huang (1998) - gender was a significant factor that differentiates students' perceptions of biology learning environments; girls perceive classroom environment more favourably than boys. Goel (2004) girls had much higher educational aspirations than boys. Rao (1970) - results showed that pupil's who have a favourable attitude towards the school are likely to have good habits of study and tend to be well disposed towards the school. Bryk and Schneider (2002); Wang and Holcombe (2010); Bryk et al., (2010) - four systems interact in ways that support or undermine school improvement efforts: professional capacity; order, safety and norms; parent-school community ties; and instructional guidance.

\section{Home Environment}

Kapani and Rao's (2007) - research shows significant role that family functioning plays in relation to attachment style and psychological distress. Mathur and Pareekh (2003) - results indicate that family pathology followed by ineffective parenting and family interaction patterns are the major contributors of problem behavior among adolescents. Warner (2008) - found that negative effects of stress at home lingers and affects teenagers' academic performance at school. Feld's (2011) - study suggests that emphasizing the association between parent or student relationships and student life satisfaction is important. Verma et al., (2002) - one context of school stress is the time that children spend doing homework.

\section{SIGNIFICANCE OF THE STUDY}

A review of the literature for this study shows enough evidence related to Adolescent Stress, the School Environment and the Home Environment. The long-standing call to improving environmental conditions at home and at school is twofold: (a) enhancing nurture and care and (b) reducing exposure to and countering the impact of non-nurturing environments. Changes within the education system are taking place, but Indian adolescents face a highly competitive examination system that determines their college entrance and access to desirable career choices. Today's Indian child could be under tremendous pressure as they live in a highly competitive environment, both in terms of school and home, with both parents and teachers having very high expectations of their or each child that goes through the school system. Students' school work almost always suffers when their school and home lives become stressful.

More research needs to be done in the area of adolescent stress as related to both home and school. Hence, this study has been undertaken. This and further research will be eye-openers for all psychologists interested in this area.

\section{Statement of Problem:}

The problem of the present study is to study Adolescent Stress in relation to Grade, Gender, School and Home Environments. 


\section{METHODOLOGY}

\section{Objectives of Study:}

To examine the difference in adolescent stress along grades, To examine the difference in adolescent stress along gender, To study a correlation between adolescent stress and the school environment, and To study a correlation between adolescent stress and the home environment.

\section{Research Design:}

Co-relational research design was used for this study (Kumar, 2005).

\section{Variables under Study:}

The variables were as follows (Kumar, 2005; Aron et al., 2006): Adolescent Stress, School Environment, Home Environment and Demographic variables: grades IX and XI; genders Female and Male.

\section{Hypotheses:}

The Hypotheses, as derived from the literature review, were as follows:

1. Adolescent Stress would be significantly higher for Grade XI students as compared to Grade IX students.

2. Adolescent Stress would be significantly higher for Female students as compared to Male students.

3. There would be a significant positive correlation between Adolescent Stress and School Environment.

4. There would be a significant positive correlation between Adolescent Stress and Home Environment.

\section{Sampling Procedure:}

Stratified random sampling method was used for this study. The student population for this study was taken from the city of Aurangabad, Maharashtra, India. A student population of Grades IX and XI was chosen because these students would be appearing for a Board Exam the following year (in Grades X and XII respectively). Schools and colleges were identified from the city of Aurangabad. Proportionate geographical stratified sampling was done based on a map of Aurangabad and dividing it into four parts, namely North, South, East and West. Schools were identified in each of the four parts (five schools from each part of Aurangabad). Twenty schools in all were approached with letters and several follow-up phone calls. Finally, six Englishspeaking medium schools agreed to participate in this study. The sample of this study constituted 620 students with a break-up as follows: In all, 353 students attempted the four inventories from Grade IX (156 Females and 197 Males) with a mean age of 13.89; and 267 students attempted the four inventories from Grade XI (136 Females and 131 Males) with a mean age of 15.96. 


\section{Study of Adolescent Stress In Relation To Grade, Gender and Perceived School and Home Environments}

\section{Tools:}

The tools used were as follows:

Adolescent Stress Questionnaire (ASQ) (Byrne, Davenport \& Mazanov, 2007):

The ASQ is a broadly based instrument which allows adolescents to report their own exposure to a wide span of stressors and to report, as well, the extent to which any stressor experience has constituted a psychological challenge for them as individuals. The 10 dimensions reflect adolescent stress, which are qualitatively consistent with the contemporary literature on the stressfulness of adolescence (Byrne et al., 2007). The ASQ has one scale, a 5-point Likert type scale from (1=Not at all stressful (or is irrelevant to me); $2=\mathrm{A}$ little stressful; $3=$ Moderately stressful; 4=Quite stressful; and 5=Very stressful) was used for scoring., with 58 items belonging to 10 dimensions namely: Stress of Home Life, Stress of School Performance, Stress of School Attendance, Stress of Romantic Relationships, Stress of Peer Pressure, Stress of Teacher Interaction, Stress of Future Uncertainty, Stress of School/Leisure Conflict, Stress of Financial Pressure, Stress of Emerging Adult Responsibility. The minimum possible score is 0 point and the maximum possible score is 296 point. Approximately 25 minutes is required to attempt this inventory.

Test-retest reliability over a single week time period showed correlations ranged between 0.68 (Stress of Financial Pressure) and 0.88 (Stress of Home Life). Three criterion measures (anxiety, depression and self-esteem) correlated strongly and in the expected directions with one another showing concurrent criterion validity of the ASQ. The instrument shows good reliability both internally and across repeat testing.

The researcher has conducted a pilot study to check the relevancy of the contents in the test, to check language difficulty, understanding of contents and timing, from four different schools from each of the four areas on the map of Aurangabad. This was conducted on 20 participants; 10 from Grade IX and 10 from Grade XI. Participants were able to understand the questionnaire well and attempted the ASQ without any problem. It was felt that since participants did not have a problem attempting the ASQ, a further adaptation of the test would not be required.

\section{Adolescent Life Events Stress Scale (ALESS) (Aggarwal et al., 2007):}

The 41 item-containing adolescent life event stress scale based on Holmes and Rahe's (1967) social readjustment rating scale and student stress scale (DeMeuse, 1985) was administered to the students by the investigators using an 'independent' measure. The ALESS was administered to 156 adolescents for formulation and 102 adolescents for validation. A third set of 112 adolescents was used to compare ALESS scores with child behavior checklist scores and parental stress scores due to life events or life-change. Life-change unit scores are used in this study; one composite score could be safely calculated. The minimum possible score is 0 point and the maximum possible score is 1353 points. Approximately 15 minutes is required to attempt this inventory. 


\section{Study of Adolescent Stress In Relation To Grade, Gender and Perceived School and Home Environments}

The comparison showed a strong positive correlation with Child Behaviour Check List (Achenbach, 1983 - CBCL) scores, a model fit of $\left(r^{2}=0.32\right)$ and an ability to predict the CBCL scores (above cutoff value) using the stress scores $=37.5+0.05$; and a weak positive correlation with parental stress (Pearson's coefficient $=0.011$ ) due to life events.

The researchers (Agarwal et al., 2007) found Cronbach's alpha for all domains in excellent range except for the relocation domain for which it was in the fair to good range. Thus, the instrument is satisfactorily valid.

\section{School Environment Inventory (SEI) (Misra, 2002):}

The School Environment Inventory (SEI) is an instrument designed to measure the psycho-social environment of schools perceived by the students. It provides a measure of the quality and quantity of the cognitive, emotional and social support that has been available to the students during their school life in terms of teacher-pupil interactions. The SEI can be used to appraise the perceptions of students, and to measure the quality of the learning environment that pervades the classroom. The SEI has one scale with 70 items belonging to six dimensions of the school environment - Creative Stimulation, Cognitive Encouragement, Permissiveness, Acceptance, Rejection and Control. The instrument requires individuals to tell the frequency with which a particular teacher - student interaction or behaviour is expressed in his or her school. They had to assign 4 marks to 'Always'. 3 marks to 'Often', 2 marks to 'Sometimes' and 1 mark to 'Rarely' and zero to no responses. The minimum possible score is 0 point and the maximum possible score is 395 points. Approximately 25 - 30 minutes is required to attempt this inventory.

The split-half reliabilities for various dimensions of the school environment ranged between .67 and .92. The scale inter-correlations for SEI scores were between -.01 to .77. Examination of the SEI revealed that a composite score can be safely calculated. The SEI possesses content validity as measured with the help of views expressed by judges; criterion-related validity could not be established. Thus, the instrument is satisfactorily valid.

\section{Home Environment Inventory (HEI) (Misra, 2003):}

The Home Environment Inventory (HEI) is an instrument designed to measure the psycho-social environment of home as perceived by children. It provides a measure of the quality and quantity of cognitive, emotional and social support that has been available to the child within the home environment.

The instrument requires students to tell the frequency - multiple choice type items - with which a particular parent-child interaction behaviour has been observed by them in their homes, that is, he/she is requested to tell whether a particular parental behaviour (as mentioned in the item) occurs - 'mostly', 'often', 'sometimes', 'least', and 'never'. The HEI has one scale with 100 items belonging to ten dimensions - Control, Protectiveness, Punishment, Conformity, Social 


\section{Study of Adolescent Stress In Relation To Grade, Gender and Perceived School and Home Environments}

isolation, Reward, Deprivation of Privileges, Nurturance, Rejection and Permissiveness. There are 5 cells where frequency of occurrence of a particular behaviour had to be given. The individual had to assign 4 marks to 'mostly', 3 marks to 'often', 2 marks to 'sometimes' 1 mark to 'least' and, 0 marks to 'never' responses. The minimum possible score is 0 point and the maximum possible score is 395 points. Approximately 25 - 30 minutes is required to attempt this inventory.

Split half reliabilities (corrected for length) were worked out separately for all the ten dimensions and ranged from .73 to .95. Inter-correlations among HEI scales were between -.04 to .88. Observations show that eight coefficients of correlations are moderate/high. One composite score could be safely calculated.

The HEI possesses content validity as measured with the help of views expressed by judges. Criterion related validity could not be established because of the lack of appropriate external criteria. Thus, the instrument is satisfactorily valid.

\section{Data Collection:}

The standard procedure of collection of data was done. Data was collected from a cross section of students from six different schools and colleges in the city of Aurangabad, in the form of questionnaires. Questionnaire administration was conducted in whole class groups during class time and fully supervised; so far as possible, this was undertaken at the same time for all classes participating within a single school (to avoid the possibility of collusive responses).This was done by the researcher alone, in calm, quiet surroundings. All standard procedures of test administration was maintained, data was collected over a period of two to two-and-a-half hours in each school. The following shows the number of students that attempted the:

ASQ inventory: 605 students; ALESS inventory: 600 students;

SEI inventory: 620 students; and HEI inventory: 620 students.

Procedure for Data Analysis: Data was entered on Excel sheets. Both Classes IX and XI data was entered in separate books of Microsoft Excel. Analysis was done along the Hypotheses. The data was checked for normality (Skewness, Minimum scores and Maximum scores); Means, SDs, ttest values and Pearson's correlation were computed using SPSS 17.0 for Windows. Responses to certain statements that were left out by the student's were not included.

The analysis of the scores for the ASQ, ALESS, SEI and HEI was done by obtaining the Mean and Standard Deviation, the scores t-test for independent samples and Pearson's Correlation Coefficient was computed between the scores for the ASQ and SEI, ASQ and HEI; between the scores for the ASQ and HEI, ASQ and HEI. 


\section{RESULTS AND DISCUSSION}

\section{GRADE-WISE PERFORMANCE ON ADOLESCENT STRESS}

Hypothesis 1: Adolescent Stress would be significantly higher for Grade XI students as compared to Grade IX students.

The results reveal that there is significantly higher Adolescent Stress for Grade XI students than Grade IX students.

Table 1: Grade-wise performance on ASQ

\begin{tabular}{|l|l|l|l|l|l|l|}
\hline Grades & Group Statistics for ALESS & Ns & Means & SDs & 't' values & p-Values \\
\hline Grade IX & ALESS & 344 & 456.62 & 229.17 & $2.55^{* *}$ & .011 \\
\hline Grade XI & ALESS & 256 & 508.71 & 270.37 & & \\
\hline
\end{tabular}

**. Significant at the 0.01 level (2-tailed)

The performance of Grade XI students on the ASQ was higher $(\mathrm{M}=142.86, \mathrm{SD}=39.25)$ than Grade IX students $(\mathrm{M}=124.34, \mathrm{SD}=44.21), t(603)=5.33, p=.000$. The Grade-wise comparison denotes that there is a significant difference of Adolescent Stress as measured by the ASQ for Grades IX and XI. The following graph shows a clear difference between Grades IX and XI in terms of stress for the ASQ Grade XI having higher stress levels than Grade IX.

Figure 1: Bar-graph for Grade-wise performance of Adolescent Stress on ASQ

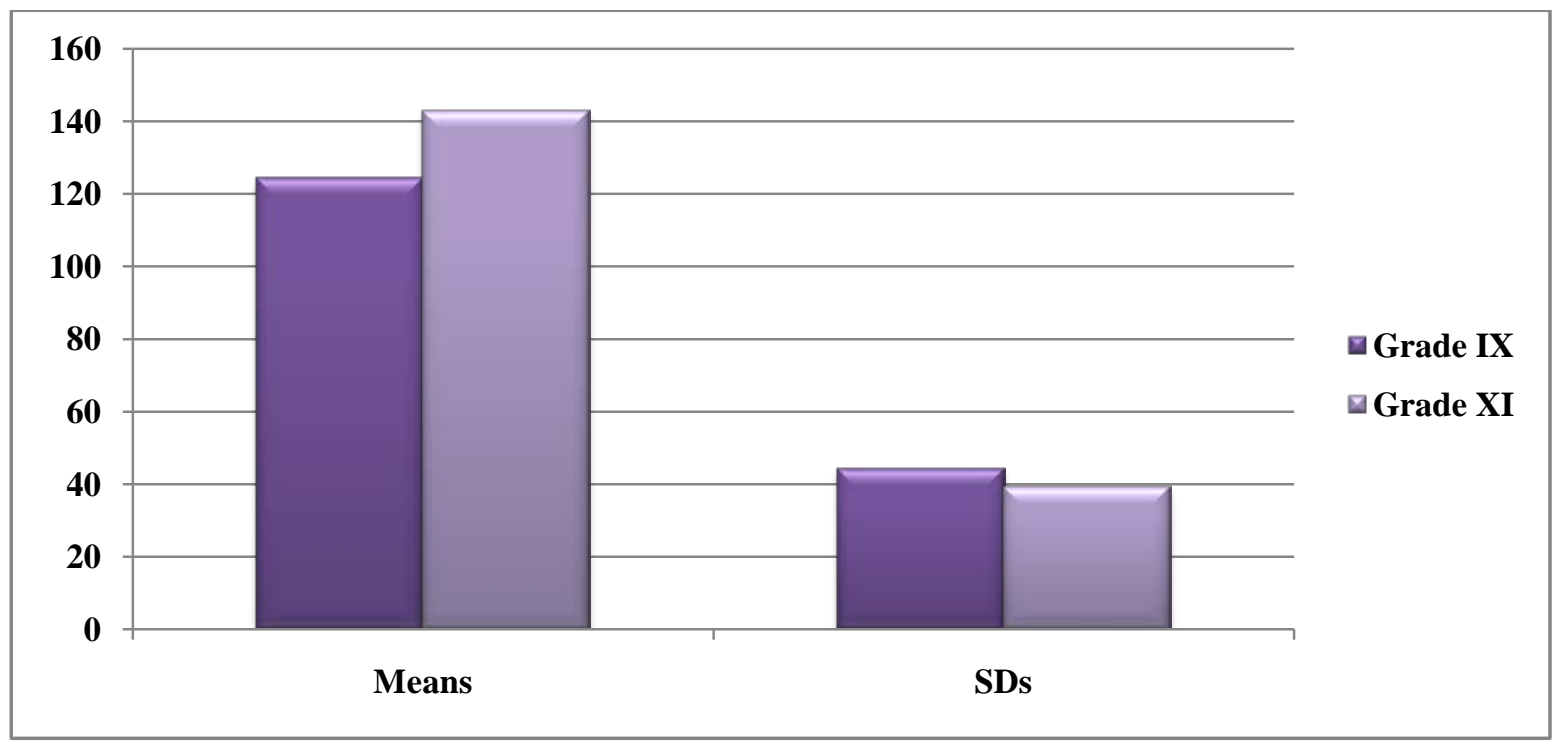


Table 2: Grade-wise performance on ALESS

\begin{tabular}{|l|l|l|l|l|l|l|}
\hline & \multicolumn{2}{|c|}{} & & & & \\
Grades & Group Statistics for ASQ & Ns & Means & SD & 't' values & p-Values \\
\hline Grade IX & ASQ & 351 & 124.34 & 44.21 & $5.33^{* *}$ & .000 \\
\hline Grade XI & ASQ & 254 & 142.86 & 39.25 & & \\
\hline
\end{tabular}

**. Significant at the 0.01 level (2-tailed)

The performance of Grade XI students on the ALESS was higher $(\mathrm{M}=508.71, \mathrm{SD}=270.37)$ than Grade IX students ( $\mathrm{M}=456.62, \mathrm{SD}=229.17), t(603)=2.55, p=.000$. The Grade-wise comparison denotes that there is significant difference of adolescent stress as measured by ALESS for Grades IX and XI. The results reveal that there is significantly higher adolescent stress for Grade XI students than Grade IX students.

In the study by Aggarwal et al (2007) when they considered adolescence as an age when the child is striving for independence, it was worthwhile to see the correlation between scores on adolescents' stress life event scale and those reported by the parents. Though the stress occurring in the life of the adolescent showed some degree of overlap with that of stress in the parent's life, a degree of independence was observed among the stress scores. Events related to relationships, deviance, relocation, family and parenting, ambiguous, distressful, autonomy, accident and illness events are found to be stressful in the life of a young adolescent in this study. The following graph shows a clear difference between Grades IX and XI in terms of stress for the ALESS; Grade XI having higher stress levels than Grade IX. Hence, Hypothesis 1 is accepted suggesting that there is a significant difference in Adolescent Stress showing Grade XI students with significantly higher stress as compared to Grade IX students.

Figure 2: Bar-graph for Grade-wise performance of Adolescent Stress on ALESS

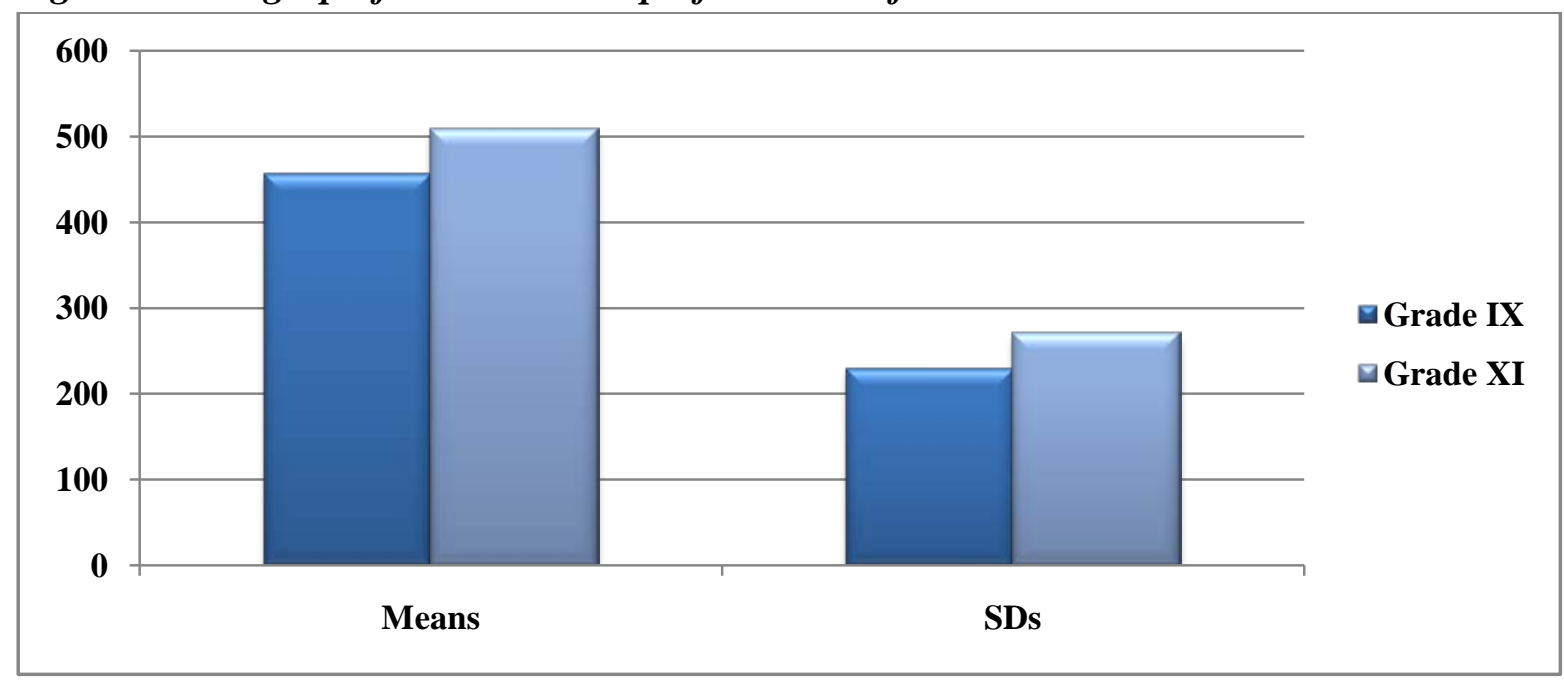

(c) The International Journal of Indian Psychology, ISSN 2348-5396 (e)| ISSN: 2349-3429 (p) | 191 


\section{Study of Adolescent Stress In Relation To Grade, Gender and Perceived School and Home Environments}

Dinesh \& Kumari (2010) found more number of children with severe stress at the age of 14 whereas the majority of the children from ages 13 to 15 showed moderate or severe level of stress than any other age groups. The researchers suggest from their study, that in every age, more than $90 \%$ of the school children of the State are facing above normal levels of stress and tension. These results are different to my study where students aged 16 or 17 years of age (Grade XI) were found to be highly stressed in comparison to students aged 14 or 15 years of age (Grade IX).

From the above study, it is clear that stress has an adverse effect on students. The results of the present study show that in relation to adolescent stress and Grades IX and XI, students may be prone to stress because of an impending Board Examination (both IX and XI will be approaching Board Examinations in Grade X and XII respectively) which they have to face. Grade XI students have to make career choices and decisions have to be made. More responsibilities may have to be shouldered by them as they grow up. Financial responsibilities may have to be taken on in terms of considering expenses for college or university education; in some cases loans may have to be taken by parents if students decide to study abroad.

They may be under more stress than Grade IX students as this is a turning point in their lives in several other areas such as attraction to the opposite sex; in Grade IX it could be that students are just beginning to become aware of the opposite sex which could lead to an attraction or forming of friendships or trying to get themselves noticed by someone they are attracted to. Teaching methods are different in both Grades; In Grade IX they are taught all subjects from English, to Mathematics, to Science, to Social Studies, to Languages etc. In Grade XI, students go into different 'streams' from Arts, to Commerce, to Science. Grade XI students have already diversified into a particular area which would lead to them to an area of their choice of career. Also their environments are very open and diversity is great; Grade IX students are given less freedom, they have to follow certain rules both at home and at school whereas Grade XI students, being young adults are given more freedom to express their ideas, more freedom to move about and do things; they are treated as young adults and not as children. Hence, any or all of these factors could play a part in adding stress in the lives of Grade XI students as compared to Grade IX.

\section{GENDER-WISE PERFORMANCE ON ADOLESCENT STRESS}

Hypothesis 2: Adolescent Stress would be significantly higher for Female students as compared to Male students.

The results reveal that there is no significant difference in Adolescent Stress for Gender. 
Table 3: Gender-wise performance on ASQ

\begin{tabular}{|l|l|l|l|l|l|l|}
\hline Genders & Group Statistics for ASQ & Ns & Means & SDs & ' $\mathbf{t}$ ' values & p-Values \\
\hline Female & ASQ & 290 & 131.67 & 39.39 & 0.24 & 0.809 \\
\hline Male & ASQ & 315 & 132.52 & 46.40 & 0.73 & .464 \\
\hline
\end{tabular}

**. Significant at the 0.01 level (2-tailed)

The performance of Male students on the ASQ showed minimal differences of adolescent stress $(\mathrm{M}=132.52, \mathrm{SD}=46.40)$ than Female students $(\mathrm{M}=131.67, \mathrm{SD}=39.39), t(603)=.242, p=.809$.

The Gender-wise comparison denotes that there is no significant difference of adolescent stress as measured by ASQ for Genders Female and Male. The following graph shows the Gender-wise performance on adolescent stress on ASQ:

Figure 3: Bar-graph for Gender-wise performance of Adolescent Stress on ASQ

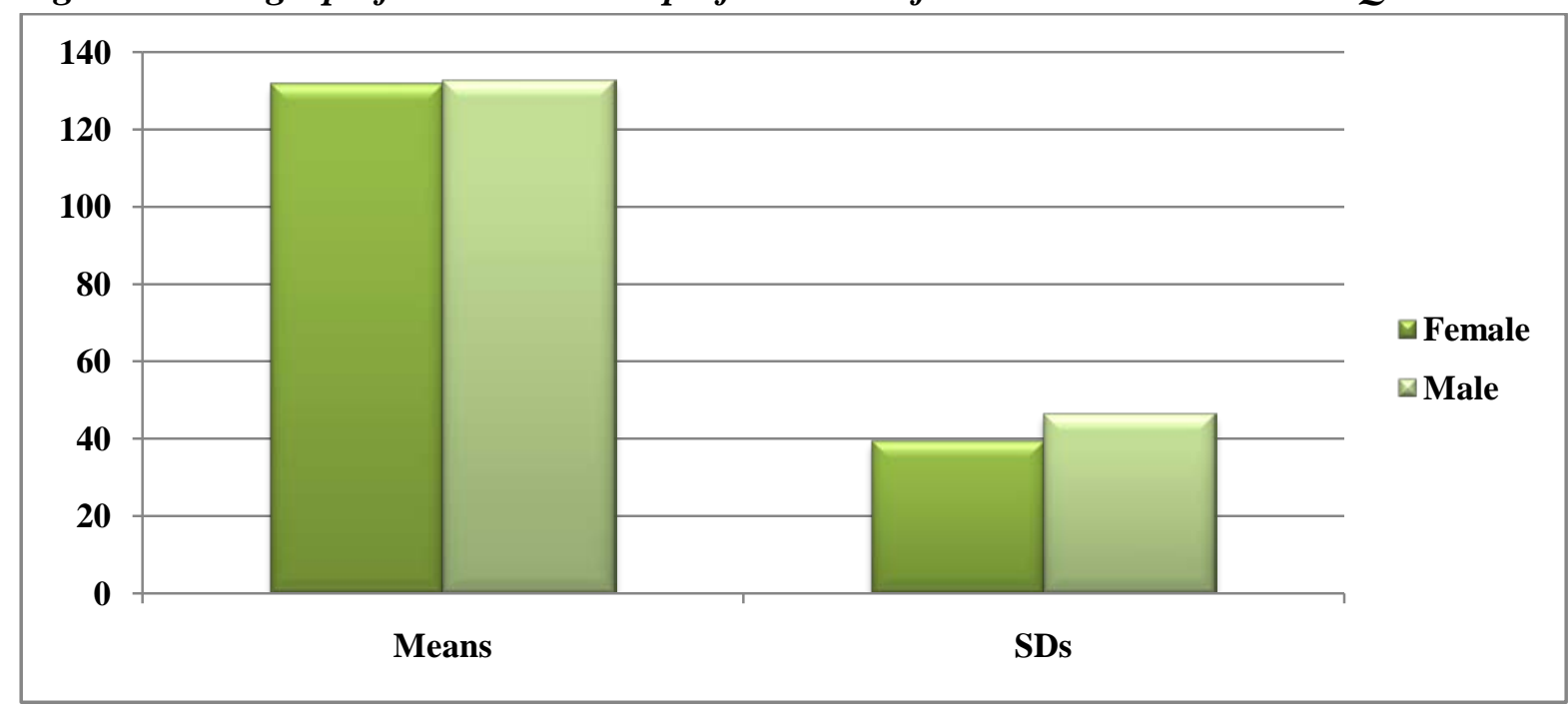

The graph shows no difference between Genders Female and Male in terms of stress for the ASQ.

Table 4: Gender-wise performance on ALESS

\begin{tabular}{|l|l|l|l|l|l|l|}
\hline Genders & Group Statistics for ALESS & Ns & Means & SDs & 't' values & p-Values \\
\hline Female & ALESS & 289 & 486.56 & 242.81 & 0.73 & .464 \\
\hline Male & ALESS & 311 & 471.67 & 254.27 & & \\
\hline
\end{tabular}

**. Significant at the 0.01 level (2-tailed)

The performance of Female students on the ALESS showed slightly higher levels of adolescent stress $(\mathrm{M}=486.57, \mathrm{SD}=243.23)$ than Male students $(\mathrm{M}=467.68, \mathrm{SD}=247.57), t(598)=.733$, $p=.464$. The Gender-wise comparison denotes that there is a low significant difference of 


\section{Study of Adolescent Stress In Relation To Grade, Gender and Perceived School and Home Environments}

adolescent stress as measured by ALESS for Genders Female and Male. The following graph shows a low difference between Genders Female and Male in terms of stress for the ALESS. Hence, Hypothesis 2 is rejected suggesting that there is no significant difference in Adolescent Stress showing Female students with significantly higher stress as compared to Male students.

Figure 4: Bar-graph for Gender-wise performance of Adolescent Stress on ALESS

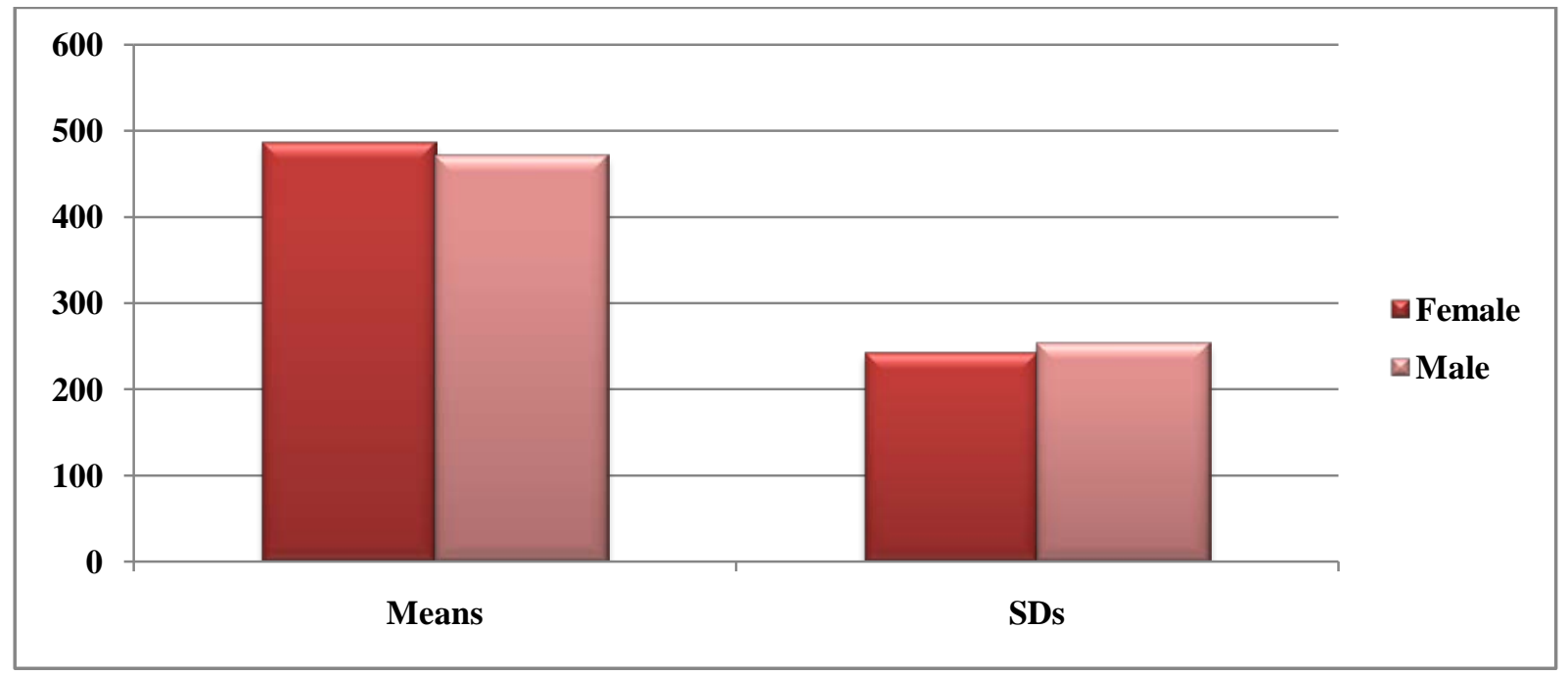

This is consistent with Gender differences reported for the original ASQ (Byrne et al., 1995) and with other literature on Gender and stress, whether in adolescents (Jensen et al., 2004; Moulds, 2003) or generally (Elliott, 2001; Tamres et al., 2002; Matud, 2004). It is a finding which is consistent with the evidence on Gender differences in the onset of such psychological disorders as major depression (Mazure \& Maciejewski, 2003) and is well recognized in the historical literature (Henderson et al., 1981). While there are no immediate reasons to explain this clearly enduring effect, the fact that the ASQ scales operate in a way which is entirely consistent with existing evidence gives real confidence that these represent meaningful dimensions of adolescent stressor experience.

In Dinesh and Kumari's (2010), study, mild to moderate level of stress is seen in more than $90 \%$ of the children studied and that levels of stress vary with age and Gender difference. The results reveal that the level of stress in children has significant relationship with their academic competence irrespective of their Gender difference. Their results also suggest that when the boys grow, their attitude and behaviour tend to change. Similarly, when physical complaints and health was studied, significant relation was seen with stress, health and academic competence particularly in boys.

In a study by Nair et al., (2004), school dropout girls have a higher prevalence of stress (11.2\%). Severe and extreme depression was $2.8 \%$ among school going girls and nil among college going 


\section{Study of Adolescent Stress In Relation To Grade, Gender and Perceived School and Home Environments}

girls. It was also observed that $22.4 \%$ of school going girls and $12.8 \%$ of school going boys had depression of various Grades.

Russell (1992) undertook a study to establish the existence of any Gender specific differences in the perceived antecedents of academic stress. Significant Gender based differences were obtained on eight of the thirty-five questions comprising the scale - performance on a test even after the test is over, inability to learn assignments, difficulty understanding assignments, being made fun of because of inability to answer a question in class, parental pressure for better Grades, pretest stress and lastly, being accused of not trying in class if performance was not up to what the school expected. In each case girl's reported greater stress than boys. This study provides strong evidence that girls and boys of high school age differentially experience the antecedents of academic stress and that adolescent girl's experience greater academic stress than boys.

Research indicates that Indian girls feel more stressed by school than boys (Verma \& Gupta, 1990; Subrahmanyam, 1986) however, girls tend to perform better academically compared to boys (Mishra, 1992), suggesting that they may adapt their daily schedules better to prepare for exams. Attitude and behaviour of girls did not show any significant relationship with level of stress. Neither the health scores, nor the attitude of the students indicated any bearing with the intensity of the stress they set to undergo. However, in boys, significance at $5 \%$ level was seen with age and attitude. This indicates that stress in children can definitely affect their academic performance and attitude in general. So also the relationship with health suggest the need for urgent steps to reduce the level of stress in children and also the causes that may lead to severe stress in children. This is in contrast to the results found in this study.

From the above studies, it is clear that stress has an adverse effect on students; the results of the present study do not show any Gender bias. Stress is similar to both Genders - Female and Male. Perhaps the pressure of future career choices, financial responsibilities, shouldering more responsibilities is taken on as a natural part of life with no adverse effects in their minds.

\section{ENVIRONMENT-WISE PERFORMANCE ON ADOLESCENT STRESS}

Hypothesis 3: There would be a significant positive correlation between Adolescent Stress and School Environment.

The results reveal that there is no significant correlation between the School Environment and Adolescent Stress. 
Table 5: Correlations for ASQ and ALESS with SEI

\begin{tabular}{|l|l|l|l|}
\hline \multicolumn{2}{|l|}{ Correlations for ASQ and ALESS } \\
\hline \multirow{2}{*}{ SEI } & r & ASQ & ALESS \\
\cline { 2 - 4 } & p-Values & .010 & -.009 \\
\cline { 2 - 4 } & Ns & .801 & .830 \\
& & 605 & 600 \\
\hline
\end{tabular}

**. Correlation is significant at the 0.01 level (2-tailed).

A very low correlation was found between SEI and ASQ, Pearson's $r(605)=.010, p>.001$. A very low correlation was found between SEI and ALESS, Pearson's $r(600)=-.009, p>.001$. Hence, Hypothesis 3 is refuted, suggesting that there is no significant correlation between Adolescent Stress and the School Environment.

Rao (1970) studied some factors related to scholastic achievement and found that there was a positive significant relationship between study habits and school attitude. Thus, a pupil who has a favourable attitude towards the school is likely to have good habits of study and tends to be well disposed towards the school.

Bryk and Schneider (2002) found evidence that schools with high relational trust (good social relationships among members of the school community) are more likely to make changes that improve student achievement. Again, Bryk et al., (2010) detail how four systems interact in ways that support or undermine school improvement efforts: professional capacity; order, safety and norms; parent-school community ties; and instructional guidance. These dimensions shape the process of teaching and learning. The authors (Bryk et al., 2010) underscore how their research has shown relational trust is the glue or the essential element that coordinates and supports these four processes, which are essential to effective school environment or climate improvement.

Although the results indicate that stress is not apparent in the school environment, and this is a positive development in the city of Aurangabad, it is suggested that educational environments remain stress-free, taking academics, sports and all other extra-curricular activities into account for an all-round development of the student. 


\section{Study of Adolescent Stress In Relation To Grade, Gender and Perceived School and Home Environments}

Hypothesis 4: There would be a significant positive correlation between Adolescent Stress and Home Environment.

Table 6: Correlations for ASQ and ALESS with HEI

\begin{tabular}{|l|l|l|l|}
\hline & & ASQ & ALESS \\
\hline \multirow{3}{*}{ HEI } & $\mathrm{r}$ & $.177^{* *}$ & -.046 \\
\cline { 2 - 5 } & $\mathrm{p}$-Values & .000 & .257 \\
\cline { 2 - 4 } & $\mathrm{Ns}$ & 605 & 600 \\
\hline
\end{tabular}

**. Correlation is significant at the 0.01 level (2-tailed).

The results suggest that there is a significant correlation between Home Environment and Adolescent Stress: A significant correlation was found for HEI and ASQ, Pearson's $r(605)=$ $.177, p<.001$. A low correlation was found for HEI and ALESS, Pearson's $r(600)=-.046, p>$ .001. Hence, Hypothesis 4 is supported suggesting that there is a significant correlation between Adolescent Stress and the Home Environment.

Padmasree's (1992) study also yielded significant correlations on stress and family support, stress and family health, stress and locus of control, family stress and locus of control, stress and academic achievement, locus of control and academic achievement. Parental ambitions, pressure to perform, inability to give space to their children to develop and express their own ideas, the busyness of daily existence including both parents working and perhaps not having or giving enough of quality time to their children are just some of the factors that need to be taken into account.

In examining the daily influence of school on adolescents' lives, Verma et al., (2002) looked at the different contexts in which Indian adolescents do academic work. As in East Asia, many middle-class Indian adolescents are enrolled in after-school coaching classes or tuitions. Tuitions were originally meant for children who were lagging behind in the syllabus due to sickness, change of school, change of Education Boards, and other factors. But with time, tuitions has become the normal pursuit of adolescents because admission to various colleges around the country has become competitive and sought after (Varma, 1998). As a result, adolescents are under pressure not only in school but also after school hours. A questionnaire study of high school students found that they spend an average of 3 - 4 hours daily in homework (Verma \& Gupta, 1990). In Indian homes homework often takes place under parental supervision. It could be expected that this continuity of adult pressure, which the child receives from teachers in school, tutors at tuition, and finally from parents at home, will result in negative emotions during the experience of homework (Verma et al., 2002).

In the adolescent group studied (12-17) by Dinesh and Kumari (2010), the academic performance or health problems did not reveal significant relationship even though the children 


\section{Study of Adolescent Stress In Relation To Grade, Gender and Perceived School and Home Environments}

revealed severe stress during the period. Their higher score in academic performance may be due to the extra coaching and vigorous training they get during the period to face the board examinations.

Kapani and Rao's (2007), research highlights the significant role that family functioning plays in relation to attachment style and psychological distress. For healthy family functioning, there needs to be a focus on strengthening the emotional bonding of members within the family; improving interpersonal communication within the family; enhancing families' relatedness with others in society and creating an atmosphere which promotes individual growth and freedom. Therefore, the major implication of the study is that it highlights the need to focus on family education and parenting skills training to prevent the development of vulnerability and to promote positive individual and familial well-being. Warner (2008) found that negative effects of stress at home lingers and affects teenagers' academic performance at school.

From the results of the present study, it is clear that stress is evident in the home environment and that parents need to take cognizance of this fact. Both school and homes need to work together to bring about as much as is possible, a stress-free environment for students to grow up in. Parents and teachers need to work together to bring about a cohesive and good learning environment for their children.

\section{CONCLUSIONS}

Hypothesis 1 is accepted suggesting that Grade XI students show significantly higher Adolescent Stress as compared to Grade IX students.

Hypothesis 2 is rejected suggesting that there is no significant difference in Adolescent Stress for Genders (Female and Male).

Hypothesis 3 is rejected suggesting that there is no significant correlation between the School Environment and Adolescent Stress.

Hypothesis 4 is accepted suggesting that there is significant correlation between the Home Environment and Adolescent Stress.

The study also brings to light the following:

The environment for Females and Males in Grade XI is highly stressed as compared to Grade IX.

\section{LIMITATIONS OF STUDY}

- This is limited to English-speaking schools only; Marathi and Hindi medium schools were not included in this study.

- A smaller number of students participating may throw up better results in terms of Gender differences and the effect on the Environment. 


\section{Study of Adolescent Stress In Relation To Grade, Gender and Perceived School and Home Environments}

\section{IMPLICATIONS AND FURTHER AVENUES FOR RESEARCH}

- This study can be replicated in different cities in India.

- This study can be replicated in rural areas of India and a comparative study of urban/rural areas could be done.

- Other Independent variables can be included such as geographical area - based on a North, South, East and West query, and regional area.

- De-stress programmes are a necessity. Schools in Aurangabad and in other cities in India, could set up De-stress Awareness Programmes wherein students could undergo this for six to eight weeks and a before/after study could be conducted to see the difference such a programme would make.

- Parental workshops need to be held in schools to increase awareness about the levels of stress their children are undergoing and the pressure that we, as adults, are putting them through. Studies pre and post could be done on this.

- Studies taking working and non-working mothers into account as a variable could throw up different results for consideration.

\section{REFERENCES}

Aggarwal, S., Prabhu, H.R.A., Anand, A., \& Kotwal, A. (2007). Stressful life events among adolescents: The development of a new measure. Indian Journal of Psychiatry, 49, 96102.

Aron, A., Aron, E.N. \& Coups, E.J. (2006). Statistics for psychology. (4 ${ }^{\text {th }}$ edition). Australia: Pearson Education and Dorling Kindersley Publishing, Inc.

Bandura, A. (1964). The stormy decade: fact or fiction? Psychology in the Schools (1), 224-231.

Bouma, E.M.C. (2010). The Sensitive Sex - Depressive symptoms in adolescence and the role of gender, genes and physiological stress responses. Promotores: Prof. Dr. A.J. Oldehinkel, Prof. Dr. J. Ormel. Copromotor: Dr. H. Riese. Gebruik a.u.b. deze link om te verwijzen naar dit document: http://irs.ub.rug.nl/ppn/326986111

Bryk, A.S. \& Schneider, B. (2002). Trust in Schools: A core resource for improvement. New York: Russell Sage.

Bryk, A.S., Sebring, P.B., Allensworth, E., Luppescu, S. \& Easton, J.Q. (2010). Organizing schools for improvement: Lessons from Chicago. Chicago: University of Chicago Press.

Byrne, D. G., Davenport, S. C., \& Mazanov, J. (2007). Profiles of adolescent stress: The development of the adolescent stress questionnaire (ASQ). Journal of Adolescence, 30(3), 393-416.

Byrne, D.G., \& Mazanov, J. (2002). Sources of stress in Australian adolescents: Factor structure and stability over time. Stress and Health, 18, 185-192.

Byrne, D.G., Byrne, A.E., \& Reinhart, M.I. (1995). Personality, stress and the decision to commence cigarette smoking in adolescence. Journal of Psychosomatic Research, 39, $53-62$.

Dinesh, S., \& Kumari, S.S. (2010). Prevalence of stress among school children in Kerala. Retrieved on 4.1.2012 from http://www.articlesbase.com/mental-healtharticles/prevalence-of-stress-among-school-children-in-kerala-1868702.html

Elliot, M. (2001). Gender differences in causes of depression. Women and Health, 33, 163-177. 


\section{Study of Adolescent Stress In Relation To Grade, Gender and Perceived School and Home Environments}

Feld, L.D. (2011). Student Stress in High-Pressure College Preparatory Schools. Honors Theses - All. Paper 685. http://wesscholar.wesleyan.edu/etd_hon_theses/685

Freud, S. (1925). Three contributions to the sexual theory. Nervous and Mental Disease Monograph Series, No. 7. New York: Nervous and Mental Disease Publishing Co.

Goel, S.P. (2004). Effect of gender, home and environment on educational aspirations. Journal of Community Guidance and Research, 21(1), 77-81.

Hall, G.S. (1916). Adolescence. 2 vols. New York: Appleton.

Jensen, E.N., Sveback, S., \& Gotestam, K.G. (2004). A descriptive study of personality, health and stress in high school students (16-19 years old). European Journal of Psychiatry, 18, 153-162.

Kapani, A.R.M., \& Rao, K. (2007). Attachment Style in Relation to Family Functioning and Distress in College Students. Journal of the Indian Academy of Applied Psychology, 33(1), 15-21.

Kohlberg, L. (1963). The development of children's orientations toward a moral order. Vita Humana (6), 11-33.

Kumar, R. (2005). Research Methodology. (2 ${ }^{\text {nd }}$ edition), Australia: Pearson Education and Dorling Kindersley Publishing Inc.

Lele, R.P., \& Sachdev, P. (2001). A study of academic performance and attitudes to learning of secondary school students in relation to their perception of the academic climate in their school. Journal of Educational Research and Extension, 38(4), 1-13.

Liang, B. \& Spencer, R. (2011). $21^{\text {st }}$ Century Athenas: aligning achievement and well-being. Centre for Research on Girls at Laurel School. Published on November 16, 2011 by Sherrie Bourg Carter, Psy.D. in High Octane Women. Prometheus Books, 2011.

Manoharan \& Sundaram, M.A. (2003). Certain school variables as related to classroom climate and teacher's teaching effectiveness as perceived by higher secondary students. Journal of Educational Research and Extension, 40(1), 1-6.

Mathur, M., \& Pareekh, K. (2003). Adolescent's problem behavior: A study of family risk factors. Indian Journal of Psychometry and Education, 34(1), 59-66.

Matud, M.P. (2004). Gender differences in stress and coping styles. Personality and Individual Differences, 37, 1401-1415.

Mazure, C. M., \& Maciejewski, P. K. (2003). The interplay of stress, gender and cognitive styles in depressive onset. Archives of Women's Mental Health, 6, 5-8.

Mishra, K.N. (1992). A comparative study of achievement motivation and scholastic achievement in relation to self-concept. The Indian Journal of Social Work, LII (1), 139142.

Mishra, M. (2002). Perception of classroom environment of middle school children. Indian Psychological Review, 58(2), 79-84.

Misra, K.S.M. (2003). Manual for Home Environment Inventory. Lucknow: Ankur Psychological Agency.

Mohanty, B., \& Pani, B. (1979). Effect of student-teacher classroom interaction on the academic performance of students. Psychological Studies, 24(1), 35-39.

Moulds, J.D. (2003). Stress manifestation in high school students: An Australian sample. Psychology in the Schools, 40, 391-402.

Nair, M.K., Paul, M.K., \& John, R. (2004). Prevalence of depression among adolescents. Indian Journal of Paediatrics 71(6), 523-524. [serial online] 2004 [cited 2007 Feb 17]; Available from: http://www.ijppediatricsindia.org/article.asp?issn=0019-5456;year=2004 


\section{Study of Adolescent Stress In Relation To Grade, Gender and Perceived School and Home Environments}

Padmasree, J. V. (1992). Stressful life events in school systems and educational development in children. M. Phil., Home Science. Sri Venkateshwara University.

Parfenoff, S.H., \& Jose, P.E. (1989). Measuring daily stress in children. Paper presented at the biennial meeting of the Society for Research Development in Child Development, Kansas City, Missouri, April 1989.

Rao, G.D. (1970). A study of some factors related to scholastic achievement. Indian Journal of Psychology, 45(2), 99-120.

Russell, J.W. (1992). Gender Specific Differences in the Perceived Antecedents of Academic Stress. http://files.eric.ed.gov/fulltext/ED364492.pdf

Subrahamanyam, S. (1986). Academic adjustment and scholastic attainment of secondary school children. Journal of Research and Extension, 22(3), 159-169.

Tamres, L. K., Janicki, D., \& Helgeson, V. S. (2002). Sex differences in coping behavior: A meta-analytic review and an examination of relative coping. Personality and Social Psychology Review, 6, 2030.

Varma, P.K. (1998). The great Indian middle class. New Delhi: Penguin.

Verma, S., \& Gupta, J. (1990). Some aspects of high academic stress and symptoms. Journal of Personality and Clinical Studies, 6(1), 7-12.

Verma, S., Sharma, D., \& Larson, R.W. (2002). School stress in India: Effects on time and daily emotions. International Journal of Behavioural Development, 26(6), 500-508.

Wang, M., \& Holcombe, R. (2010). Adolescents' perceptions of school environment, engagement, and academic achievement in middle school. American Educational Research Journal, 47, 633-662.

Warner, J. (2008). Teen Stress at Home Lingers in School, WebMD Health News, Reviewed By Louise Chang, MD, May 15. http://www.medicinenet.com

Waxman, H.C., \& Huang, S.Y.L. (1998). Classroom learning environments in urban elementary, middle and high schools. Learning Environment Research, 1(1), 95-113.

Ying, S., Fangbiao, T., Jiahu, H., \& Yuhui, W. (2010). The Mediating Effects of Stress and Coping on Depression Among Adolescents in China. Journal of Child and Adolescent Psychiatric Nursing, 23(3), 173-180. Article first published online: 12 AUG 2010 DOI: $10.1111 / \mathrm{j} .1744-6171.2010 .00238 . x$. 